\title{
Effect of Quenching Strategy and Nb-Mo Additions on Phase Transformations and Quenchability of High-Strength Boron Steels
}

\author{
IRATI ZURUTUZA, ${ }^{1,2}$ NEREA ISASTI, ${ }^{1,2}$ ERIC DETEMPLE ${ }^{3}$ \\ VOLKER SCHWINN, ${ }^{3}$ HARDY MOHRBACHER, ${ }^{4,5}$ \\ and PELLO URANGA (1) ${ }^{1,2,6}$ \\ 1.-Materials and Manufacturing Division, CEIT-Basque Research and Technology Alliance \\ (BRTA), 20018 Donostia/San Sebastián, Basque Country, Spain. 2.-Mechanical and Materials \\ Engineering Department, Universidad de Navarra, 20018 Donostia/ \\ San Sebastián, Basque Country, Spain. 3.-AG der Dillinger Hüttenwerke, 66763 Dillingen/ \\ Saar, Germany. 4.-NiobelCon BV, 2970 Schilde, Belgium. 5.-Department of Materials \\ Engineering (MTM), KU Leuven, 3001 Leuven, Belgium.6.-e-mail: puranga@ceit.es
}

The application of direct quenching after hot rolling of plates is being employed in the production of ultra-high-strength hot rolled plates. When heavy gauge plates are produced, the complexity involve in achieving high cooling rates in the plate core is increased and the formation of undesirable soft phases within martensite is common. In the current paper, both direct quenching and conventional quenching (DQ and $\mathrm{CQ}$ ) processing routes were reproduced by dilatometry tests and continuous cooling transformation (CCT) diagrams were built for four different high-strength boron steels. The results indicate that the addition of Mo and Nb-Mo suppresses the ferritic region and considerably shifts the CCT diagram to lower transformation temperatures. The combination of DQ strategy and the Mo-alloying concept provides the best option to ensure hardenability and the formation of a fully martensitic microstructure, and to avoid the presence of soft phases in the center of thick plates.

\section{INTRODUCTION}

The practice of direct quenching (DQ) after hot rolling is gaining importance in industry in the production of high-strength plates. ${ }^{1}$ The $\mathrm{DQ}$ process avoids the re-austenitization step that is usual for the conventional quenching (CQ) procedure, enabling significant energy savings to be made, and leading to economic benefits and productivity improvements. ${ }^{2-4}$ In $\mathrm{CQ}$, the rolled material is cooled down to room temperature and reheated before being quenched. However, DQ strategy is based on the application of fast cooling immediately after a thermomechanically controlled hot rolling process. This is an efficient process used to improve the strength and toughness of steels by pancaking the austenite below the recrystallization stop

(Received March 18, 2021; accepted June 18, 2021) temperature (RST) prior to quenching. ${ }^{5}$ In addition, given that the reheating process is obsolete, DQ strategy could prove to be beneficial in preserving microalloying elements in solid solution that in turn could precipitate during subsequent tempering treatment. ${ }^{5}$ The main objective of $\mathrm{DQ}$ is to create entirely martensitic microstructures by applying the highest possible cooling rate. Although cooling rates above $100^{\circ} \mathrm{C} / \mathrm{s}$ could be reached through current cooling facilities, the effective cooling rate for thicker gauges at the plate core is considerably lower and so ensuring full martensitic structures throughout the thickness becomes challenging. ${ }^{6}$ Therefore, depending on rolling conditions and the alloy concept, there may be a risk of forming undesirable soft phases such as ferrite and bainite. Furthermore, residence time in the cooling device may be excessively long in the case of thicker 
gauges, lowering the output of the rolling mill. In this case, applying the $\mathrm{CQ}$ process might prove to be economically more attractive.

Alloying with molybdenum and/or boron effectively helps reduce the critical cooling speed for martensite formation, while the combined addition of microalloying elements such as $\mathrm{Ti}, \mathrm{Nb}, \mathrm{Mo}$, and $\mathrm{B}$ to carbon steels may provide an increase in strength through microstructural refinement and precipitation hardening as well as hardenability and final microstructural modification. ${ }^{7-9}$ The use of $\mathrm{B}$ as an alloying element increases strength by obstructing ferrite nucleation at austenite grain boundaries, thus encouraging the formation of bainitic/martensitic microstructures even at low cooling rates. ${ }^{10}$ The combined addition of $\mathrm{B}$ and $\mathrm{Nb}$ as well as Mo in turn encourages the segregation of boron into the austenite grain boundaries, thus ensuring the effectiveness of boron with regard to hardenability. ${ }^{11-14}$ Microalloying of $\mathrm{Nb}$ is standardly used for retarding austenite recrystallization during rolling, both by solute drag and by strain-induced precipitation. ${ }^{15,16}$ This leads to an accumulation of deformation in austenite, ensuring grain size refinement of the final microstructure and improving mechanical properties. ${ }^{17}$ Molybdenum alloying increases strength and toughness properties in carbon steels due to the effect it has on encouraging the formation of low-temperature transformation products such as bainite and martensite, ${ }^{18}$ and by avoiding temper embrittlement. Besides the direct effects of molybdenum, the combination of $\mathrm{Nb}$ and Mo leads to pronounced synergetic effects, while Mo significantly contributes to austenite pancaking by solute drag during hot rolling. This effect is even greater in combination with niobium, as the martensitic substructures are formed in the previously pancaked austenite grains, ${ }^{6},{ }^{19,20}$ combining drag and straininduced precipitation mechanisms. Molybdenum also delays precipitation of niobium during austenite conditioning, making a higher amount of solute niobium available for precipitation during tempering treatment.

Recently, the impact of adding $\mathrm{Nb}$ and Mo to the microstructure and tensile/toughness properties was evaluated in high-strength quenched and tempered boron steels. ${ }^{21,22}$ In these studies, the addition of $0.5 \%$ Mo to a $0.16 \% \mathrm{CMnB}$ base alloy was proven to be crucial in ensuring yield strength values above $900 \mathrm{MPa}$ and low ductile-to-brittle transition temperatures after direct quenching and tempering treatment $\left(600^{\circ} \mathrm{C}\right.$ during $\left.300 \mathrm{~s}\right)$. The results shown in references ${ }^{21}$ and $^{22}$ suggest that the most relevant contribution to strength and toughness was related to microstructural refinement. Additional refinement is associated with austenite conditioning, which can be achieved by combining Mo with $0.025 \% \mathrm{Nb}$.

Given that direct quenching is a relatively new process in plate production, the metallurgical effects of $\mathrm{Mo}$ and $\mathrm{Nb}$ alloying on high-strength direct- quenched boron steels have not been widely reported in the literature and further knowledge regarding its effect on phase transformation is needed. To this end, DQ and CQ strategies were simulated by dilatometry tests in the current study. Continuous cooling transformation (CCT) diagrams were derived for all compositions and the impact of thermomechanical treatment on phase transformation, the resulting microstructure and hardness was evaluated accordingly. Finally, the feasibility of the direct quenching strategy was evaluated, and the optimum alloy concept/thermomechanical cycle selected.

\section{EXPERIMENTAL PROCEDURE}

Four carbon steels containing $0.16 \% \mathrm{C}$ and 20 ppm boron were selected, three of them microalloyed with $\mathrm{Nb}, \mathrm{Mo}$, and NbMo. The $\mathrm{Nb}$ level was $0.026 \%$ and Mo content $0.5 \%$. All the steels were alloyed with $\mathrm{Ti}$ to ensure the full effect of boron. Table I shows the chemical composition of the steels.

Uniaxial compression tests were performed in a Bähr DIL805A/D quenching and deformation dilatometer, with solid cylinders of $5 \mathrm{~mm}$ in diameter and $10 \mathrm{~mm}$ in length being used. The specimens were subjected to two different thermomechanical schedules (direct quenching and conventional quenching) in order to simulate different rolling and cooling strategies, represented schematically in Fig. 1. Both cycles included reheating treatment at $1200^{\circ} \mathrm{C}$ for $10 \mathrm{~min}$ followed by two deformation passes of a 0.3 strain and at a strain rate of $1 \mathrm{~s}^{-1}$ at $1175^{\circ} \mathrm{C}$ and $1050^{\circ} \mathrm{C}$, in order to obtain a fine recrystallized austenite. As for the direct quenching (DQ) cycle (Fig. 1a), a third deformation pass of $\varepsilon=0.3$ was applied below the non-recrystallization temperature at $870^{\circ} \mathrm{C}$, with the aim of accumulating deformation in the austenite prior to phase transformation. Finally, continuous cooling was applied ranging from $0.1^{\circ} \mathrm{C} / \mathrm{s}$ to maximum cooling $\left(0.1^{\circ} \mathrm{C} / \mathrm{s}, 0.5^{\circ} \mathrm{C} / \mathrm{s}, 1^{\circ} \mathrm{C} / \mathrm{s}, 2^{\circ} \mathrm{C} / \mathrm{s}\right.$, $5^{\circ} \mathrm{C} / \mathrm{s}, 10^{\circ} \mathrm{C} / \mathrm{s}, 20^{\circ} \mathrm{C} / \mathrm{s}, 50^{\circ} \mathrm{C} / \mathrm{s}, 100^{\circ} \mathrm{C} / \mathrm{s}$ and maximum cooling). Regarding conventional quenching strategy (CQ), following the first two deformation passes at $1175^{\circ} \mathrm{C}$ and $1050^{\circ} \mathrm{C}$, the specimens were then cooled down slowly $\left(1^{\circ} \mathrm{C} / \mathrm{s}\right)$ to room temperature. Afterwards, a second austenitization treatment was

Table I. Chemical composition of the steels studied (wt.\%)

\begin{tabular}{|c|c|c|c|c|c|c|}
\hline Steel & C & $\mathbf{S i}$ & Mn & Mo & $\mathbf{N b}$ & B \\
\hline $\mathrm{CM}_{1}$ & 0.1 & 0.3 & 1. & - & - & 0.0022 \\
\hline $\mathrm{CMnNbB}$ & 0.16 & 0.29 & 1.05 & - & 0.026 & 0.0019 \\
\hline CMnMoB & 0.16 & 0.28 & 1.07 & 0.5 & - & 0.0022 \\
\hline $\mathrm{CMnNbMoB}$ & 0.16 & 0.31 & 1.07 & 0.5 & 0.026 & 0.0018 \\
\hline
\end{tabular}


Effect of Quenching Strategy and Nb-Mo Additions on Phase Transformations and Quenchability of High-Strength Boron Steels

Direct Quenching (DQ)

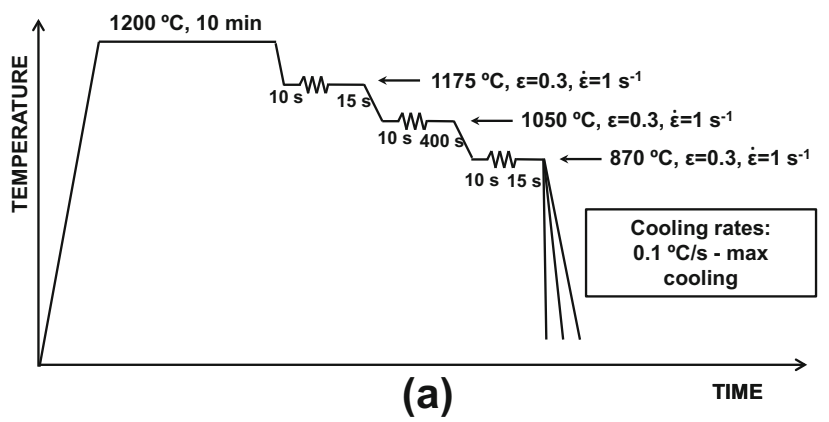

Conventional Quenching (CQ)

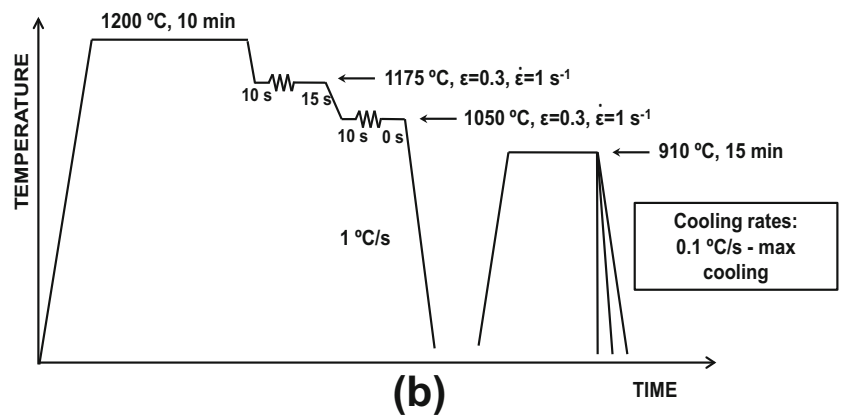

Fig. 1. Thermomechanical schedules. (a) Direct quenching and (b) conventional quenching performed using the dilatometer.

applied at $910^{\circ} \mathrm{C}$ for $15 \mathrm{~min}$ and, finally, controlled cooling was applied at cooling rates from $0.1^{\circ} \mathrm{C} / \mathrm{s}$ to maximum cooling.

Initial and final transformation temperatures were calculated from the dilatation curves, ${ }^{23}$ and the lever rule was applied to the dilatometry curves in order to measure evolution of the transformed fraction. ${ }^{24}$ This rule relies on extrapolating the linear expansion behavior from the temperature regions where no transformation occurs and subsequently assuming proportionality between the fraction of decomposed austenite and the length change observed. ${ }^{25}$ In the current study, the transformation start and finish temperatures were defined as being represented at 5 and $95 \%$ transformed fractions, while for their part, the dilatometry specimens were sectioned along their longitudinal axis by selecting the region corresponding to a maximum area fraction of nominal strain and reduced strain gradient. $^{25,26}$

The transformed microstructures obtained from the dilatometry samples were etched in $2 \%$ Nital and the austenite prior to transformation was revealed by etching in a solution of saturated picric acid and $\mathrm{HCl}$. Samples were characterized by optical microscopy (OM, LEICA DM15000 M, Leica microsystems) and field-emission gun scanning electron microscopy (FEGSEM, JEOL JSM-7100F). In addition, the austenite grain sizes prior to transformation were measured using the mean equivalent diameter method, with all specimens finally undergoing the Vickers hardness test, using a 1-kg load.

\section{RESULTS AND DISCUSSION}

\section{Phase Transformations}

\section{Austenite Conditioning}

Table II summarizes the austenite grain size parameters measured for all chemical compositions and thermomechanical cycles. Together with the average grain size, $\mathbf{D}_{\gamma}$, calculated as the average equivalent area diameter, values for surface area per unit volume, $S_{\mathrm{v}}$, and grain thickness (for DQ cycles) values were also reported. In the case of direct quenched $\mathrm{CMnB}$ steel, the austenitic structure could not be properly reconstructed, due to the formation of a bainitic/martensitic microstructure rather than a fully martensitic one. Consequently, a reliable austenite grain size measurement was not possible in that case. In the case of all alloys and in terms of $\mathrm{D}_{\gamma}$, the DQ process results in coarser mean austenite grain size than in the CQ process. After DQ processing, austenite morphology in the Mo and $\mathrm{Nb}$ alloyed steels is pancaked, whereas this is rather equiaxed in the case of the CMnB base alloy. This results in closest values for both $S_{\mathrm{v}}$ and thickness measurements, especially in the case of Mo bearing grades. Conversely, the CQ process normalizes the microstructure, leading to equiaxed austenite grain morphology in all steel alloys subject to research. The re-austenitizing condition applied in the current study $\left(910^{\circ} \mathrm{C} / 900 \mathrm{~s}\right)$ prevents significant austenite grain growth before quenching, resulting in relatively smaller average austenite grain size. Furthermore, the addition of molybdenum causes a significant reduction in mean austenite grain size in the DQ processed steels. This is related to more pronounced pancaking of the austenite due to strong solute drag by molybdenum during austenite conditioning. In $\mathrm{CQ}$ processed steels, however, molybdenum alloying appears to have the opposite effect, as the average austenite grain size is slightly larger than in the Mo-free steels. On one side, boron segregation at the grain boundary suppresses nucleation of the new phase by reducing the grain boundary energy. On the other side, molybdenum reduces the interface mobility between ferrite and austenite. ${ }^{27}$ During re-transformation, austenite nucleates from carbon-rich phase (pearlite) and at grain boundaries, especially at triple points. If the latter is delayed due to solute boron and low interface mobility, the nuclei from the carbon-rich phase have more room to grow by experiencing less growth competition. The reduction of grain size at higher austenite temperature can be due to Mo 
Table II. Austenite grain quantification for all steel grades and thermomechanical cycles

\begin{tabular}{|c|c|c|c|c|c|}
\hline \multirow[b]{2}{*}{ Steel } & \multicolumn{3}{|c|}{ DQ } & \multicolumn{2}{|c|}{$\mathbf{C Q}$} \\
\hline & $\boldsymbol{D}_{\gamma}(\boldsymbol{\mu} \mathbf{m})$ & $S_{v}\left(\mu \mathbf{m}^{-1}\right)$ & Thickness $(\boldsymbol{\mu m})$ & $\boldsymbol{D}_{\gamma}(\mu \mathbf{m})$ & $S_{\mathbf{v}}\left(\mu \mathbf{m}^{-1}\right)$ \\
\hline CMnB & - & - & - & $19 \pm 1$ & 0.10 \\
\hline $\mathrm{CMnNbB}$ & $45 \pm 5$ & 0.04 & $37 \pm 4$ & $23 \pm 2$ & 0.11 \\
\hline CMnMoB & $32 \pm 3$ & 0.07 & $23 \pm 2$ & $25 \pm 2$ & 0.10 \\
\hline $\mathrm{CMnNbMoB}$ & $32 \pm 4$ & 0.07 & $22 \pm 2$ & $25 \pm 2$ & 0.07 \\
\hline
\end{tabular}

solute drag, as was demonstrated by Militzer et al. ${ }^{28}$ However, this requires molybdenum to diffuse sufficiently to the austenite grain boundaries, which depends on the diffusional range at a given re-heat temperature and time. For the reheating conditions in the current manuscript, the diffusional range is much too small in comparison with grain diameters, so this effect could be negligible. It should be noted that industrially practiced re-austenitizing conditions typically use somewhat higher temperatures and longer times. Niobium microalloying was found to be very effective in limiting austenite grain coarsening by boundary pinning under such treatment conditions, having a beneficial effect on toughness of the quenched steel. ${ }^{29}$

\section{Final Microstructure and Vickers Hardness}

Figure 2 shows an example of the microstructures obtained by optical and FEGSEM microscopy of the CMnMoB steel after DQ processing and cooling rates of $0.1^{\circ} \mathrm{C} / \mathrm{s}, 5^{\circ} \mathrm{C} / \mathrm{s}$, and $50^{\circ} \mathrm{C} / \mathrm{s}$. The lowest cooling rate $\left(0.1^{\circ} \mathrm{C} / \mathrm{s}\right)$ produces a microstructure that mainly contains ferrite and bainite (see Fig. 2a). Ferrite formation is suppressed at higher cooling rates in the case of this particular steel. Second phases such as MA islands and pearlite are dispersed in the ferrite matrix (Fig. 2d) at a slow cooling rate, while when an intermediate cooling rate of $5^{\circ} \mathrm{C} / \mathrm{s}$ is applied, the microstructure becomes predominantly bainitic (see Fig. $2 b$ and e). From a cooling rate of $50^{\circ} \mathrm{C} / \mathrm{s}$ the microstructure becomes fully martensitic (Fig. 2c and f), with this microstructural evolution generally being similar among all the steels and cycles applied, albeit with significant differences regarding the critical cooling rates required to induce the microstructural changes observed.

Analysis of the hardness evolution as a function of the cooling rate (Fig. 3) identifies two plateaus and a transition range. At low cooling rates, the hardness is on a low level and only slightly increasing with the cooling rate, whereas hardness saturates on an upper plateau at higher cooling rates. The maximum hardness of full martensite with a carbon content of $0.15 \%$ is calculated to be around $465 \mathrm{HV},{ }^{29}$ while the upper plateau value approaches $420 \mathrm{HV}$, remaining below the calculated maximum-likely due to self-tempering. In the case of the Mo-alloyed steels, the plateau values are lower following the $\mathrm{CQ}$ process than after the $\mathrm{DQ}$ process. The $\mathrm{CMnMoB}$ steel clearly achieves the highest hardness at a given cooling rate irrespective of the process variant, and the critical cooling rates marking the end of the lower plateau as well as the onset of the upper plateau are significantly lowered by alloying of the molybdenum. In the case of $\mathrm{CMnMoB}$ steel cooling rates above $20^{\circ} \mathrm{C} / \mathrm{s}$, the formation of a fully martensitic microstructure is established, and in that of the NbMo grade, lower hardness values are measured than for Mo steel. When $\mathrm{Nb}$ is added to a Mo microalloyed steel, higher strain accumulation is achieved in the austenite, leading to an increase in the ferrite nucleation sites, which encourages a faster nucleation of the bainitic laths and increases the critical cooling rate required to obtain pure martensite. As for the $\mathrm{CMnB}$ and $\mathrm{CMnNbB}$ steels, a gradual change from ferritepearlite microstructures to more bainitic ones causes a slight hardness increment for cooling rates up to $20^{\circ} \mathrm{C} / \mathrm{s}$, although rates above $100^{\circ} \mathrm{C} / \mathrm{s}$ are needed to obtain a fully martensitic microstructure in the Mo-free steels. In the case of the CMnMoB steel and cooling rates above $20^{\circ} \mathrm{C} / \mathrm{s}$, the hardness remains almost constant (around $420 \mathrm{HV}$ ), this being attributed to the formation of a fully martensitic microstructure. Therefore, the addition of molybdenum decreases the critical cooling rate in order to create martensitic microstructures.

From a practical point of view, hardness after direct or conventional quenching will be lower in industrial samples due to two factors. First, as final plate thickness increases the through-thickness temperature gradients and cooling rate differences from surface to center will be higher. Second, the auto-tempering process will be enhanced in thicker gauges, reducing the hardness levels in quenched samples towards the centerline areas.

\section{Alloy and Processing Effects on CCT Diagrams}

Figure 4 shows CCT diagrams for all the alloys subject to research and both quenching processes. The molybdenum alloyed steels reveal a clear shift of the ferrite phase field towards longer times, and the bainite phase field is also depressed. It is important to note that boron microalloying by itself cannot fully prevent ferrite formation in these steels at technically realistic cooling rates, as only in combination with molybdenum alloying can there be 
Effect of Quenching Strategy and Nb-Mo Additions on Phase Transformations and Quenchability of High-Strength Boron Steels
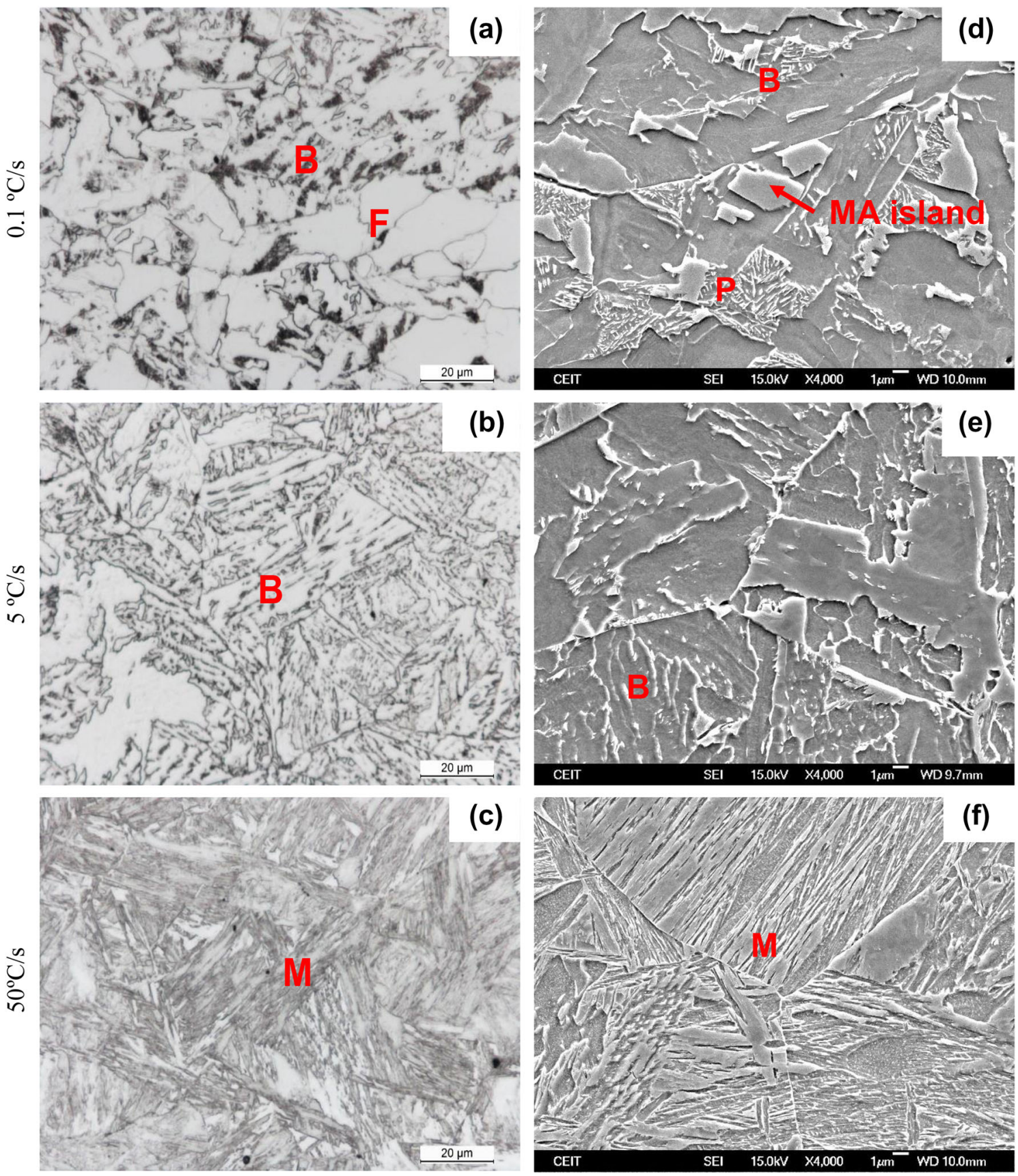

Fig. 2. Optical $(a-c)$ and FEGSEM (d-f) micrographs of the CMnMoB steel grade after direct quenching.

sufficient suppression of ferrite nucleation. The major impact of molybdenum alloying on hardenability relies on two effects. Firstly, molybdenum reduces the nucleation rate of allotriomorphic ferrite somewhat independently of temperature in the range of diffusional transformations, as demonstrated by Kinsman and Aaronson. ${ }^{30}$ Secondly, a major solute drag effect acts on the carbon-rich interphase boundaries that attract molybdenum, due to its high binding energy with carbon.
The segregation of solute B atoms at the austenite grain boundaries also efficiently suppresses the nucleation of allotriomorphic ferrite, although this effect is lost when boron forms $\mathrm{Fe}_{23}(\mathrm{C}, \mathrm{B})_{6}$ or $\mathrm{Fe}_{2} \mathrm{~B}$ precipitates. ${ }^{12-14}$ The formation of such boride precipitates is encouraged by higher boron addition; therefore, the optimum boron addition range for hardenability is particularly narrow, namely 5-15 $\mathrm{ppm}$, and the boron addition of $20 \mathrm{ppm}$ in these steels already carries the risk of $\mathrm{Fe}_{23}(\mathrm{C}, \mathrm{B})_{6}$ precipitation. Recent work by Ishikawa et al. ${ }^{31}$ has 

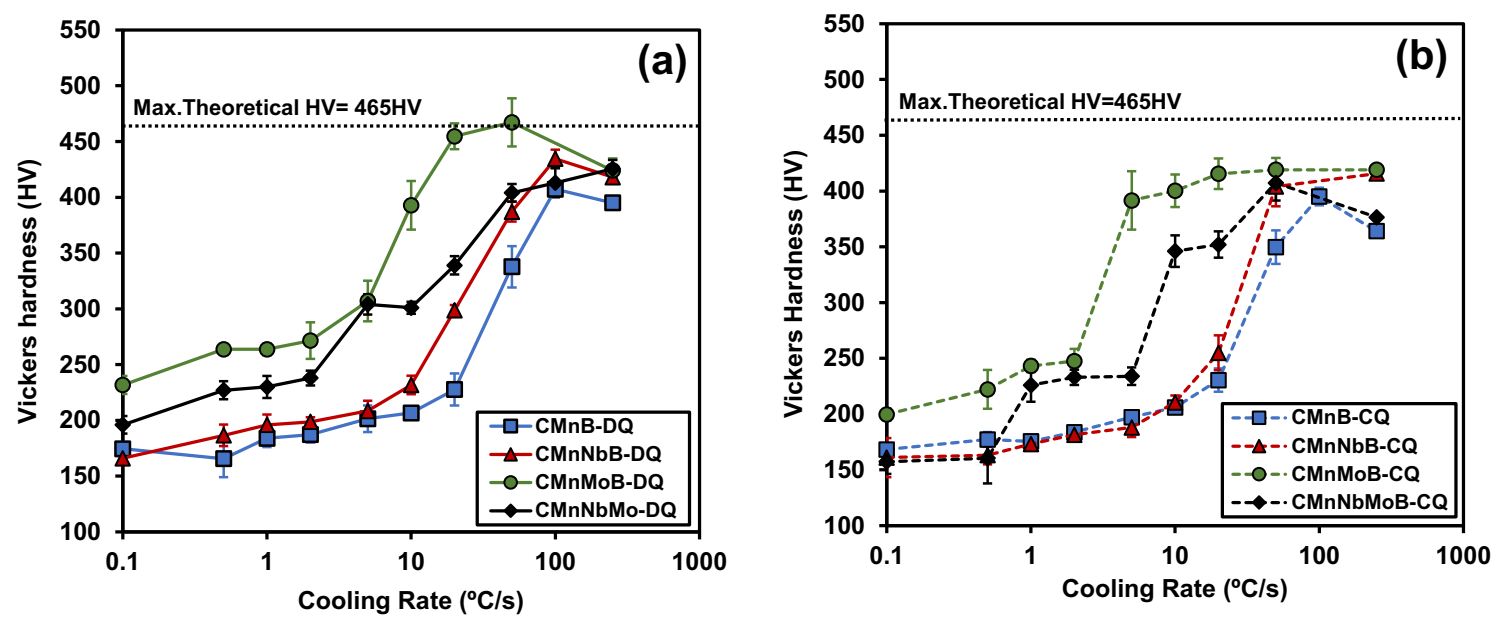

Fig. 3. Vickers hardness as a function of cooling rate for (a) direct quenching (DQ) and (b) conventional quenching (CQ) cycles.

indicated that the addition of $20 \mathrm{ppm} \mathrm{B}$ to $0.15 \% \mathrm{C}$ Mn steel reduces the critical cooling rate to around $50{ }^{\circ} \mathrm{C} / \mathrm{s}$ in Mo-free steel under CQ conditions, this being in line with current data. For its part, the addition of $0.5 \%$ Mo was shown to reduce the critical cooling rate to below $20{ }^{\circ} \mathrm{C} / \mathrm{s}$, which is also congruent with current data, while the hardenability synergy between the two alloying elements was noted in the fact that molybdenum additions below $0.75 \%$ suppress precipitation of $\mathrm{Fe}_{23}(\mathrm{C}, \mathrm{B})_{6} .{ }^{31}$

The formation of carbon-rich phases such as pearlite and MA particles can only be observed for the slowest cooling rates in Mo-free steels. For its part, the diffusion-based partitioning of carbon required is greatly suppressed by the presence of molybdenum and, hence, pearlite does not form in Mo-alloyed steels.

The effect of niobium microalloying on transformation behavior is ambiguous as, on the one hand, niobium that remains solute in austenite after hot rolling is known to lower the transformation temperature, encouraging the formation of bainite or acicular ferrite; on the other hand, accumulated strain energy related to the recrystallization-inhibiting effect of niobium is a driving force behind accelerated transformation. In a recent study on the same steels, ${ }^{22}$ it was also shown that severe austenite conditioning that triggers dynamic recrystallization results in austenite grain boundaries being insufficiently protected by segregated boron, while the addition of molybdenum was found to suppress dynamic recrystallization.

In the present CCT diagrams it is evident that $\mathrm{Nb}$ microalloying in the DQ process encourages ferrite formation more than CMnB steel (Fig. 4a versus b). Similarly, for the CQ cycle, the ferritic formation is suppressed for lower cooling rates in CMnB steel than for CMnNbB steel (Fig. 4e versus $\mathrm{f}$ ). In the $\mathrm{Mo}+\mathrm{Nb}$ alloyed steel under DQ processing conditions, early ferrite formation is also completely suppressed (Fig. 4 b versus d), whereas the bainite start temperature is increased, and the nose is shifted towards shorter times when compared with the Mo-only steel (Fig. 4d versus c). The same comparison under $\mathrm{CQ}$ processing conditions indicates that the bainite phase fields are nearly identical and that only the ferrite phase field is moved to shorter times (Fig. $4 \mathrm{~g}$ versus $\mathrm{h}$ ).

In a previous paper, activation of dynamic recrystallization was reported in the case of $\mathrm{CMnNbB}$ steel, ${ }^{22}$ with formation of these recrystallized grains during deformation at low temperatures, leading to the transformation from austenite to polygonal ferritic grains in a bainitic matrix. Even if deformation below $\mathrm{Tnr}$ is lower in this case, similar mechanisms could be the source of the effects observed in the DQ process. The co-addition of molybdenum successfully suppresses dynamic recrystallization and thus prevents early ferrite formation. However, the strain accumulation still encourages bainite formation, while in the CQ process strain accumulation is absent. Unlike molybdenum at the current addition level, niobium does precipitate during the $\mathrm{CQ}$ reheating cycle to near completeness, while moderately accelerated ferrite formation in $\mathrm{Nb}$ microalloyed steels is potentially caused by co-precipitation of boron with niobium. For its part, niobium has the capacity to form $\mathrm{NbB}_{2}$ precipitates which are stable at austenitizing temperature, ${ }^{32}$ although a detailed analysis using high-resolution TEM and atom probe tomography would be needed to confirm this assumption.

\section{Effect of Quenching Process on Quenchability}

It was evidently demonstrated that the addition of Mo is crucial for increasing hardenability and ensuring fully martensitic microstructures after quenching. Fig. 5 shows the comparison between the CCT diagrams corresponding to the $\mathrm{CMnB}$ and $\mathrm{CMnMoB}$ steels and DQ process. In the case of the 
Effect of Quenching Strategy and Nb-Mo Additions on Phase Transformations and Quenchability of High-Strength Boron Steels
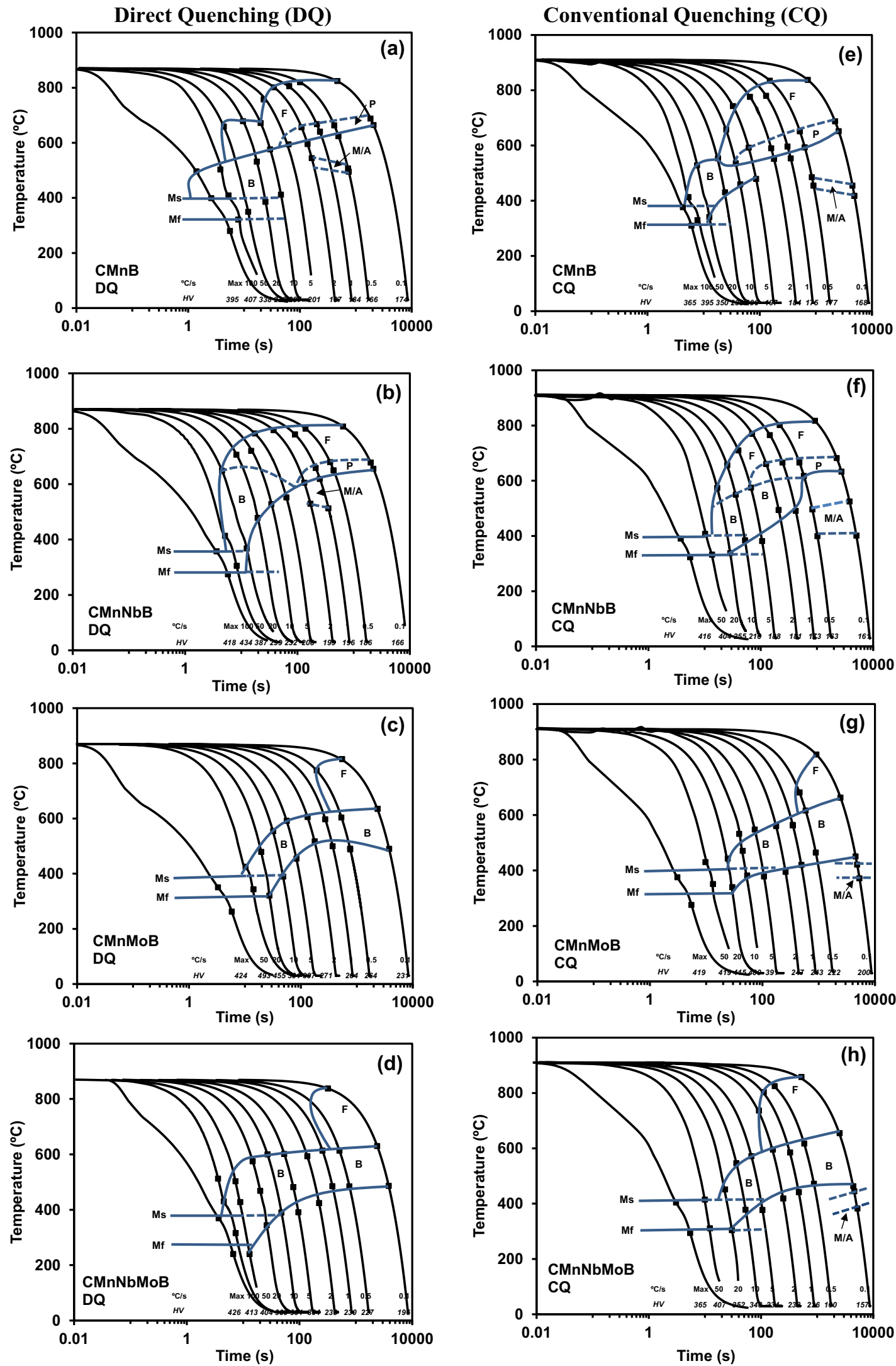

Fig. 4. CCT diagrams corresponding to $(a, e) C M n B$, (b, f) CMnNbB, (c, g) CMnMoB and (d, h) CMnNbMoB steels obtained from DQ (a-d) and $\mathrm{CQ}(\mathrm{e}-\mathrm{i})$ cycles. 


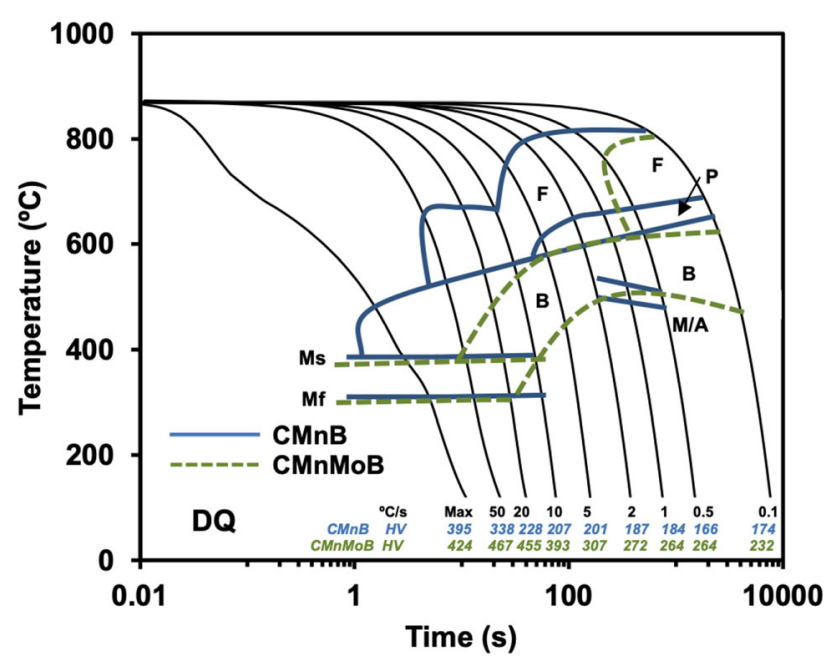

Fig. 5. Comparison between CCT diagrams corresponding to $\mathrm{CMnB}$ and $\mathrm{CMnMoB}$ steels and the direct quenching (DQ) cycle.

CMnB steel, bainitic-martensitic microstructures are formed, and a fully martensitic microstructure cannot be ensured even though maximum cooling is applied. However, in the case of the Mo steel, the martensitic phase becomes dominant at cooling rates above $20^{\circ} \mathrm{C} / \mathrm{s}$. Therefore, at $50^{\circ} \mathrm{C} / \mathrm{s}$, a significantly harder microstructure is formed in the case of Mo-alloyed steel compared with CMnB base steel (467 HV versus $338 \mathrm{HV}$ ), this being associated with the formation of martensite instead of bainite.

During industrial production of thick plates, the cooling rate in the center of the plate thickness will be significantly slower than at the surface of the plate, even though accelerated cooling is applied. For a typical final plate thickness in the range of $15-20 \mathrm{~mm}$, the cooling rate is expected to vary between $20^{\circ} \mathrm{C} / \mathrm{s}$ and $50^{\circ} \mathrm{C} / \mathrm{s}$. Thus, Fig. 6 a shows the effect of chemical composition on the evolution of a transformed fraction for a cooling rate of $20^{\circ} \mathrm{C} / \mathrm{s}$ in order to evaluate the feasibility of the different alloy concepts used in DQ processing. This is supported by Fig. 6b-e, which shows optical micrographs of the respective final microstructures.

The highest transformation temperatures are observed in the $\mathrm{CMnB}$ steel. When $\mathrm{Nb}$ is added, the transformation kinetics are initially similar to that of the $\mathrm{CMnB}$ steel, while with progressive transformation, the rate becomes increasingly delayed, shifting the microstructure to a higher fraction of bainite (Fig. 6b versus c). Alloying of $0.5 \%$ molybdenum shifts the transformation curve by approximately $200^{\circ} \mathrm{C}$ towards lower temperatures. The martensite start temperature for the current alloys was calculated to be around $440{ }^{\circ} \mathrm{C}$, with molybdenum alloying having only a marginal impact. $^{33}$ Thus, the CMnMoB steel almost completely transforms below the martensite start temperature while nonetheless experiencing some selftempering. For its part, the CMnMoNbB steel shows a fraction of about $20 \%$ transformation in the bainite region, before martensite transformation starts. This is also reflected in the micrographs (Fig. 6d versus e), insofar as hardness measurements of these microstructures resulted in values of 227.7 HV, 298.7 HV, 454.7 HV, and 339 HV for the $\mathrm{CMnB}$, CMnNbB, CMnMoB, and $\mathrm{CMnNbMoB}$ steels, respectively. The value of the fully martensitic $\mathrm{CMnMoB}$ steel is thus slightly below the theoretical maximum hardness of $465 \mathrm{HV}$ of martensite containing $0.15 \% \quad \mathrm{C}$, due to selftempering.

The effect of the quenching process on the transformation start temperatures is evaluated in Fig. 7, in order to define appropriate processing windows for full martensite transformation. In this figure, the effect of the cooling rate on transformation start temperature is only considered in the case of intermediate and high cooling rates (above $10^{\circ} \mathrm{C} / \mathrm{s}$ ). In the case of the $\mathrm{CMnB}$ grade, a completely martensitic microstructure is only obtained by the $\mathrm{CQ}$ process and then for cooling rates above $100^{\circ} \mathrm{C} / \mathrm{s}$. In $\mathrm{CMnNbB}$ steel, martensite formation requires cooling rates above $50^{\circ} \mathrm{C} / \mathrm{s}$ in the $\mathrm{CQ}$ process and $100^{\circ} \mathrm{C} / \mathrm{s}$ in the DQ process. Such high cooling rates are, however, not obtainable under industrial conditions, especially when heavier plate gauges are being produced. With the addition of $0.5 \% \mathrm{Mo}$, the critical cooling rate required for full martensite formation is reduced to much lower values of between 20 and $30^{\circ} \mathrm{C} / \mathrm{s}$ for both $\mathrm{DQ}$ and $\mathrm{CQ}$ processes, with the combined addition of $\mathrm{Nb}$ and Mo suppressing the formation of ferrite for all cooling rates above $10^{\circ} \mathrm{C} / \mathrm{s}$ (Fig. $7 \mathrm{~d}$ ). With the $\mathrm{DQ}$ process, this alloy encourages partial bainite formation for industrially relevant cooling rates, resulting in a bainite-martensite mixed microstructure. The transformation start temperatures observed in Fig. 7 are in agreement with the Vickers hardness evolution as a cooling rate function, as shown in Fig. 3.

\section{CONCLUSION}

This study analyzed the phase transformation behavior of $0.15 \% \mathrm{C}-\mathrm{MnB}$ steels that simulate direct (DQ) and conventional (CQ) quenching processes, in the course of which it became evident that boron microalloying would be insufficient for the purpose of obtaining a fully martensitic microstructure at industrially achievable cooling rates.

The addition of $0.5 \%$ molybdenum allowed the critical cooling rate to be reduced to a reasonably low level, while martensite hardness did not reach the theoretical maximum hardness of $465 \mathrm{HV}$ due to self-tempering occurring below the martensite start temperature of approximately $440{ }^{\circ} \mathrm{C}$ in these alloys.

The excellent hardenability in the $0.5 \%$ Moalloyed steel is related to intrinsic effects of molybdenum that reduce the ferrite nucleation rate and exert major solute drag on the carbon-enriched 
Effect of Quenching Strategy and Nb-Mo Additions on Phase Transformations and Quenchability of High-Strength Boron Steels

(a)
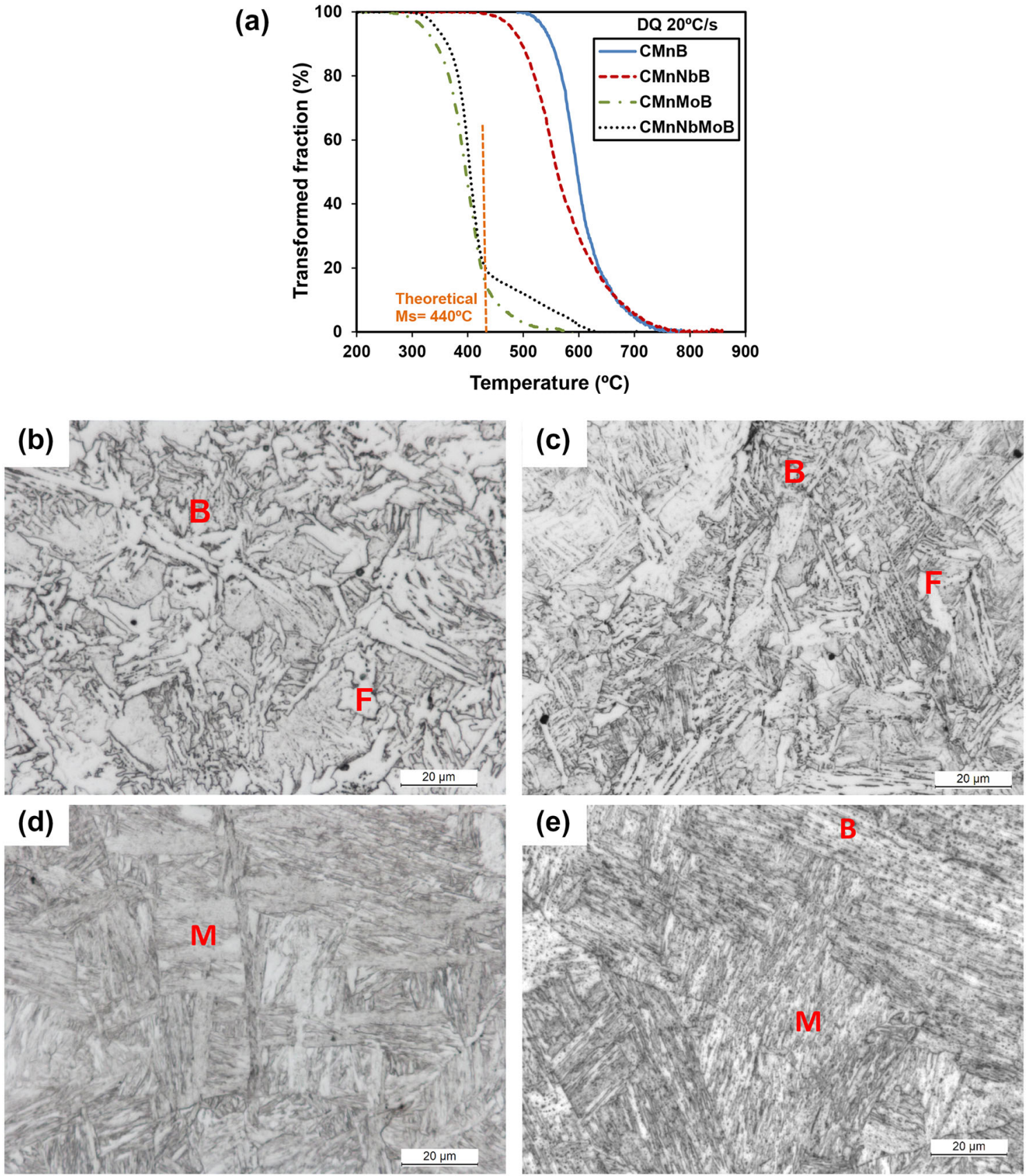

Fig. 6. (a) Evolution of transformed fraction for the $20^{\circ} \mathrm{C} / \mathrm{s}$ cooling rate and $\mathrm{DQ}$ cycle. Optical micrographs corresponding to (b) $\mathrm{CMnB}$, (c) $\mathrm{CMnNbB}$, (d) CMnMoB, and (e) CMnNbMoB steels.

interphase area. Furthermore, molybdenum enhances the efficiency of boron by preventing partial precipitation into $\mathrm{Fe}_{23}(\mathrm{~B}, \mathrm{C})_{6}$. Particularly in the DQ process, molybdenum alloying suppresses dynamic recrystallization, thus enhancing the probability of boron-depleted new austenite grain boundaries.

Identical steel alloys are less hardenable under DQ conditions than under CQ conditions, and this is due to accumulated strain and a larger total grain boundary surface of pancaked austenite offering more nucleation sites for ferrite in the DQ process. Both effects are further encouraged by niobium microalloying.

In the $\mathrm{CQ}$ process, niobium microalloying moderately encourages ferrite formation, despite equiaxed austenite morphology and an absence of accumulated strain. It was speculated that niobium could trap part of the solute boron by co-precipitation, although this possibility has to be researched in detail in a future study. NbC precipitates, however, are considered beneficial in an industrial $\mathrm{CQ}$ 

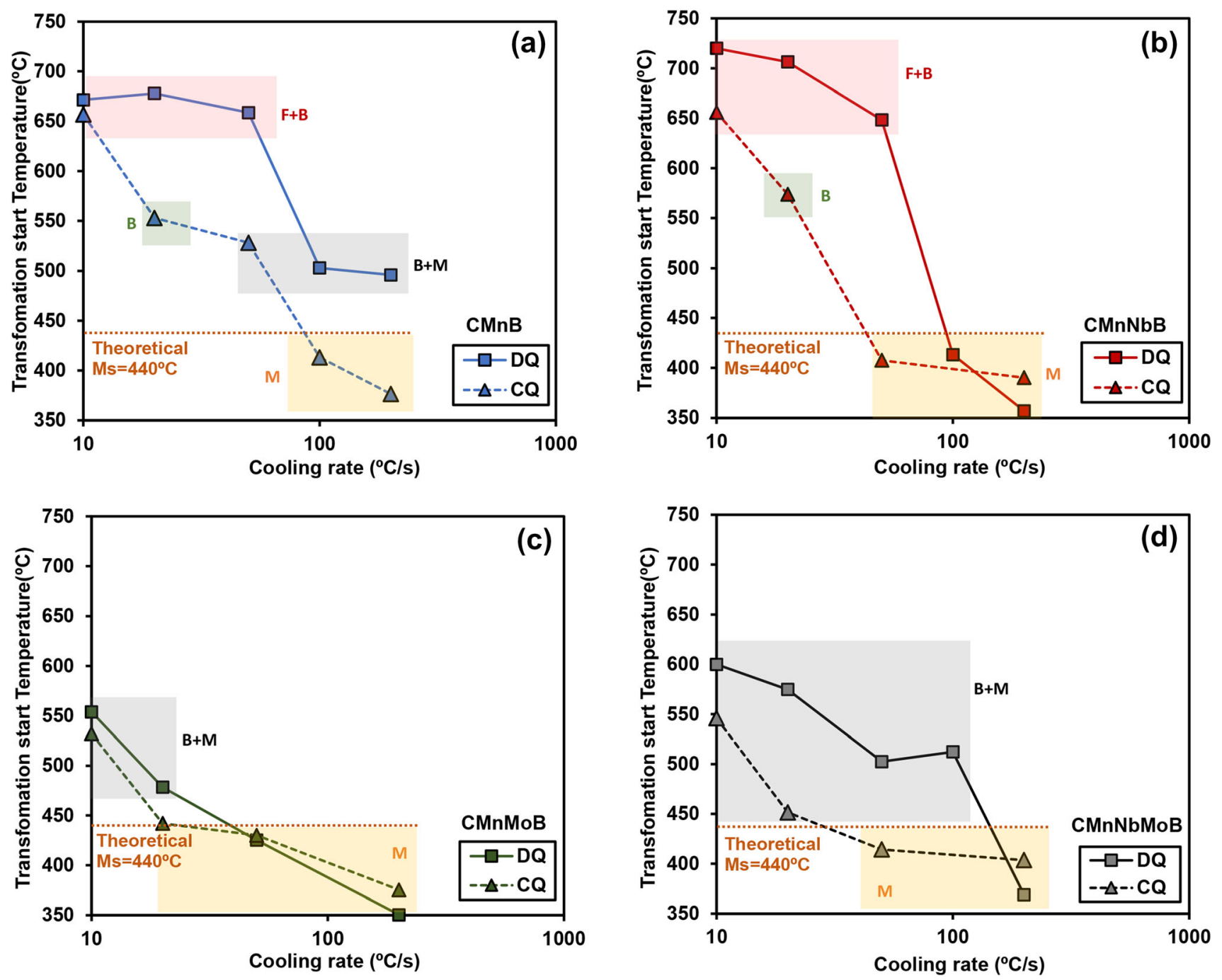

Fig. 7. Effect of cooling rate on transformation start temperature when direct quenching and conventional quenching cycles are applied for (a) $\mathrm{CMnB}$, (b) CMnNbB, (c) CMnMoB, and (d) CMnNbMoB steels.

process, as these temperature-stable particles may efficiently control austenite grain size before quenching by boundary pinning. As such, combined alloying of niobium with molybdenum provides sufficient hardenability, particularly in CQ processes.

\section{ACKNOWLEDGEMENTS}

The authors would like to express their gratitude to the International Molybdenum Association (IMOA) for funding this project.

\section{FUNDING}

Open Access funding provided thanks to the CRUE-CSIC agreement with Springer Nature.

\section{CONFLICT OF INTEREST}

The authors declare that they have no conflicts of interest.

\section{OPEN ACCESS}

This article is licensed under a Creative Commons Attribution 4.0 International License, which permits use, sharing, adaptation, distribution and reproduction in any medium or format, as long as you give appropriate credit to the original author(s) and the source, provide a link to the Creative Commons licence, and indicate if changes were made. The images or other third party material in this article are included in the article's Creative Commons licence, unless indicated otherwise in a credit line to the material. If material is not included in the article's Creative Commons licence and your intended use is not permitted by statutory regulation or exceeds the permitted use, you will need to obtain permission directly from the copyright holder. To view a copy of this licence, visit $h$ ttp://creativecommons.org/licenses/by/4.0/. 
Effect of Quenching Strategy and Nb-Mo Additions on Phase Transformations and Quenchability of High-Strength Boron Steels

\section{REFERENCES}

1. J. Hannula, J. Kömi, D.A. Porter, M.C. Somani, A. Kaijalainen, P. Suikkanen, J.R. Yang, and S.P. Tsai, Metall. Mater. Trans. 48, 5344. https://doi.org/10.1007/s11661-0174295-3 (2017).

2. A. Saastamoinen, A. Kaijalainen, T.T. Nyo, P. Suikkanen, D. Porter, and J. Kömi, Mater. Sci. Eng. 760, 346. https://doi org/10.1016/j.msea.2019.06.018 (2019).

3. J. Kömi, P. Karjalainen, and D. Porter, in Encyclopaedia of Iron, Steel and Their Alloys, ed. by R. Colás and G.E. Totten, (Boca Raton, CRC Press, 2016), p. 1109. https://doi.org/10. 1081/E-EISA-120049737.

4. A.J. Kaijalainen, P.P. Suikkanen, T.J. Limnell, L.P. Karjalainen, J.I. Kömi, and D.A. Porter, J. Alloys Compd. 577, S642. https://doi.org/10.1016/j.jallcom.2012.03.030 (2013).

5. Z.J. Xie, C.J. Shang, X.L. Wang, X.P. Ma, S.V. Subramanian, and R.D.K. Misra, Mater. Sci. Eng. 727, 200. https://d oi.org/10.1016/j.msea.2018.04.086 (2018).

6. P. Uranga, C.-J. Shang, T. Senuma, J.-R. Yang, A.-M. Guo, and H. Mohrbacher, Adv. Manuf. 8, 15. https://doi.org/10. 1007/s40436-019-00285-y (2020).

7. H. Mohrbacher, International seminar on applications of Mo in steels, ed. by CISRI and IMOA (Beijing, China, 2010), p. 74 .

8. N. Isasti, D. Jorge-Badiola, M.L. Taheri, B. López, and P. Uranga, Metall. Mater. Trans. 42, 3729. https://doi.org/10. 1007/s11661-011-0624-0 (2011)

9. G.I. Garcia, Int. Conf. Microalloying '95, (ISS, Warrendale, PA, 1995), p. 365

10. A. Larrañaga-Otegui, B. Pereda, D. Jorge-Badiola, and I. Gutiérrez, Metall. Mater. Trans. 47, 3150. https://doi.org/10. 1007/s11661-016-3465-z (2016).

11. D.T. Llewellyn, Ironmak. Steelmak. 20, 338. (1993).

12. K.A. Taylor, Metall. Trans. 23, 107. https://doi.org/10.1007/ BF02660858 (1992).

13. G. Shigesato, T. Fujishiro, and T. Hara, Metall. Mater. Trans. 45, 1876. https://doi.org/10.1007/s11661-013-2155-3 (2014).

14. Y.J. Li, D. Ponge, P. Choi, and D. Raabe, Scripta Mater. 96, 13. https://doi.org/10.1016/j.scriptamat.2014.09.031 (2016).

15. C.L. Miao, C.J. Shang, G.D. Zhang, and S.V. Subramanian, Mater. Sci. Eng. 527, 4985. https://doi.org/10.1016/j.msea.2 010.04.039 (2010).

16. C.R. Hutchinson, H.S. Zurob, C.W. Sinclair, and Y.J.M. Brechet, Scripta Mater. 59, 635. https://doi.org/10.1016/j.sc riptamat.2008.05.036 (2008).

17. N. Isasti, D. Jorge-Badiola, M.L. Taheri, and P. Uranga, Metall. Mater. Trans. 44, 3552. https://doi.org/10.1007/s116 61-013-1738-3 (2013).
18. P. Cizek, B.P. Wynne, C.H.J. Davies, and P.D. Hodgson, Metall. Mater. Trans. 46, 407. https://doi.org/10.1007/s1166 1-014-2601-x (2015)

19. J. Hannula, D.A. Porter, and A. Kaijalainen, JOM. 71, 2405. https://doi.org/10.1007/s11837-019-03478-9 (2019).

20. H. Mohrbacher, in International Symposium on the Recent Development in Plate Steels, Winter Park, Colorado (2011), p. $169-178$

21. I. Zurutuza, N. Isasti, E. Detemple, V. Schwinn, H. Mohrbacher, and P. Uranga, Metals. 11, 29. https://doi.org/10.33 90/met11010029 (2021).

22. I. Zurutuza, N. Isasti, E. Detemple, V. Schwinn, H. Mohrbacher, and P. Uranga, Metals. 11, 95. https://doi.org/10.33 90/met11010095 (2021).

23. C. Garcia de Andres, F.G. Caballero, C. Capdevila, and L.F Alvarez, Mater. Charact. 48, 101. https://doi.org/10.1016/S1 044-5803(02)00259-0 (2002).

24. R. Petrov, L. Kestens, and Y. Houbaert, Mater. Charact. 53, 51. https://doi.org/10.1016/j.matchar.2004.07.005 (2004).

25. P.A. Manohar, T.R. Chandra, and C.R. Killmore, ISIJ Int. 36, 1486. https://doi.org/10.2355/isijinternational.36.1486 (1996).

26. ABAQUS Reference Manuals: Dassault Systemes, Providence, RI, (2009).

27. F. Togashi, and T. Nishizawa, J. Jpn. Inst. Metals. 40, 12. (1976)

28. M. Militzer, in Comprehensive Materials Processing, ed. by S. Hashmi, G.F. Batalha, C.J. Van Tyne, and B. Yilbas (Elsevier Ltd., Amsterdam, 2014), Vol. 1, p. 191. https://doi. org/10.1016/B978-0-08-096532-1.00115-1.

29. H. Mohrbacher, Metals. 8, 234. https://doi.org/10.3390/met 8040234 (2018).

30. K.R. Kinsman and H.I. Aaronson, Transformation and Hardenability in Steels (Climax Molybdenum Co., Ann Arbor, 1967), p 39.

31. K. Ishikawa, H. Nakamura, R. Homma, M. Fujioka, and M. Hoshino, ISIJ Int. 58, 551. https://doi.org/10.2355/isijintern ational.ISIJINT-2017-579 (2018).

32. V.T. Witusiewicz, A.A. Bondar, U. Hecht, J. Zollinger, and T.Y. Velikanov, J. Alloys Compd. 587, 234. https://doi.org/ 10.1016/j.jallcom.2013.10.142 (2014).

33. S.M.C. van Bohemen, Mater. Sci. Technol. 28, 487. https://d oi.org/10.1179/1743284711Y.0000000097 (2012).

Publisher's Note Springer Nature remains neutral with regard to jurisdictional claims in published maps and institutional affiliations. 